\title{
The effect of early career social capital on long-term income development in Finland
}

\author{
Tomi Oinas, Petri Ruuskanen, Mari Hakala and Timo Anttila \\ Department of Social Sciences and Philosophy, University of Jyväskylä, \\ Jyväskylä, Finland
}

\section{Effect of early career social capital}

Received 12 February 2020 Revised 22 April 2020 Accepted 23 April 2020

\begin{abstract}
Purpose - In this study, the authors examine whether social capital embedded in individuals' social networks is connected to employees' long-term income development in Finland.

Design/methodology/approach - Analyses are based on 25-35-year-old employees from the Finnish Living Conditions Survey of 1994 combined with register data on earned incomes from 1995 to 2016. The authors used questions addressing the frequency of meeting parents or siblings, spending free time with co-workers and participation in associational, civic or other societal activities as measures of the extent of network capital. Ordered logistic model was used to examine whether the size and composition of social networks differ by gender and socio-economic status. Linear growth curve models were employed to estimate the effect of social capital on long-term income development.

Findings - Results indicate minor differences in network composition according to gender, but large differences between socio-economic groups. The authors found that income development was faster for those who participated in civic activities occasionally or who met their relatives or co-workers on a monthly basis, that is, for the "middle group".

Research limitations/implications - Results are generalizable only to Finnish or Nordic welfare state context. The authors' measures of social capital come from cross-sectional survey. Thus, the authors are not able to address the stability or accumulation of social capital during life course. This restriction will probably cause the authors' analysis to underestimate the true effect of social capital on earned incomes.

Practical implications - Moderate-level investments to network capital seem to be the most beneficial with regard to the long-term income development.

Social implications - The study results give support to the idea that social capital can be transformed into economic capital. The results also imply that in economic terms it is important to balance diverse forms of social capital. At the policy level, a special emphasis should be directed to employees with low-socio-economic position. These people are especially vulnerable as their low level of income is combined with network composition that hinders their further income development.
\end{abstract}

Originality/value - The combined survey and register data give unique insight on how the social capital embedded in individuals' social networks is connected with long-term income development.

Keywords Gender, Social networks, Labour market, Income, Social capital

Paper type Research paper

\section{Introduction}

During the last couple of decades, the concept of social capital has become popular in understanding economic success of individuals and communities. Generally, social capital has been defined as "connections among individuals-social networks and the norms of reciprocity and trustworthiness that arise from them" (Putnam, 2000, p. 19), Theories of social capital have separated into different approaches. Some scholars emphasize the collective

(C) Tomi Oinas, Petri Ruuskanen, Mari Hakala and Timo Anttila. Published by Emerald Publishing Limited. This article is published under the Creative Commons Attribution (CCBY 4.0) licence. Anyone may reproduce, distribute, translate and create derivative works of this article (for both commercial and noncommercial purposes), subject to full attribution to the original publication and authors. The full terms of this licence may be seen at http://creativecommons.org/licences/by/4.0/legalcode.

This study was supported by the Kone Foundation.

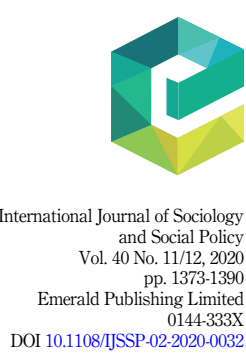


IJSSP

$40,11 / 12$

1374

dimension of the phenomena, such as the norms and trust that arise from dense community networks (Coleman, 1988) or from historical institutions and the "civicness" of the society (Putnam, 1993, 2000). They see social capital as a public good, something that benefits all members of the community. Other scholars emphasize social capital as an individual asset. Individuals who have an advantageous position in social networks benefit from the resources and opportunities embedded in their networks (Burt, 1992; Lin, 1999). Yet another group of scholars emphasize the bounded solidarity and trust within a particular status group of mutual recognition and see social capital as an asset originated from social background. Thus, individuals coming from prestigious social backgrounds may benefit more from their networks, contributing to social inequality. (Bourdieu, 1986; Portes, 1998)

The public good approach to social capital became popular in explaining the different performance of communities, regions and nation states (see, e.g. Putnam, 1993; Knack and Keefer, 1997; Putnam, 2000). The private good approach to social capital has investigated, for example, individuals' achievement of specific goals in their working life. There are several studies suggesting that social ties or social capital affects individuals' success in their working life. This can take place through, for example, enhanced job searches, early promotion or better pay (Granovetter, 1974; Lin andDumin, 1986; Podolnyand Baron, 1997; Burt, 2000).

Often, these studies have been conducted with relatively small or local data sets. Empirical evidence that links individuals' social networks and long-term work-related economic rewards by using large and representative longitudinal data sets remains surprisingly rare. In this article, we examine how the social capital embedded in individuals' early career social networks is connected with long-term income development in Nordic context. We also ask if social networks contribute to income development differently among men and women and different socio-economic groups. Growth curve analyses are based on interviews of 25-44year-old employees from the Finnish Living Conditions Survey (FLCS) of 1994, combined with register data on earned yearly income and unemployment months from 1995 to 2016. This provides a possibility to link individual-level social capital with long-term individual income development and unemployment periods.

The article is structured as follows. First, we provide a brief insight into the previous studies of the ways social capital is connected to individual performance/success within the labour market and how it is differentiated between gender and socio-economic groups. Secondly, we formulate the specific research questions and hypothesis of the study and specify the data and methods used in this study. Next, we present our findings. Finally, we conclude with the results of the study.

\section{Social capital, careers and income}

The tradition of conceptualizing social capital as an individual asset understands social capital as an additional pool of resources embedded in the social networks of individuals. Ronald Burt (1992), for example, emphasizes that through relations with colleagues, friends and other contacts, actors get opportunities to transform their financial and human capital into profit. Having wide social networks and holding an advantageous position within the networks opens up opportunities and information benefits for an individual. An advantageous position in social networks enables early access to valuable information, which facilitates the discovery of economic opportunities. A central position within a network also provides control over others. Furthermore, the referrals of social contacts are a positive force in taking advantage of those opportunities (Burt 1992, 2002; Lin 1999, 2001).

A large body of studies has examined the relationship between individuals' social networks and their working careers, such as getting a job, retaining a (better) job and pay. The seminal study is Mark Granovetter's (1974/1995) Getting a Job. A Study of Contacts and Careers. His central finding was that getting a (new) job is related to references and 
information about new job offers that are conducted through a person's social networks. Within these networks, Granovetter distinguishes between "strong" and "weak" social ties. By strong ties, he refers to close social relations that are characterized by lengthy time commitments, emotional intensity and intimacy. In other words, strong ties connect similar agents with shared identities. Weak ties, on the other hand, are characterized as more distant and less frequent than strong ties. They connect actors who move in different social circles and thus, have access to different information sources. Even if people in dense networks of strong ties are usually more aware of individuals' personal situations and may be more motivated in helping them to find a job, Granovetter postulates that weak ties are more effective in generating new labour market opportunities. Strong ties tend to overlap with the same information and contacts. The Granovetterian "strength of weak ties" lies precisely in their potential ability to transmit diverse information (Granovetter, 1973, 1983; 1995).

Similarly, social capital has been distinguished for its "bonding" and "bridging" dimension (e.g. Gittelland Vidal, 1998; Putnam, 2000). Bonding social capital refers to the relations of people who already know each other, feel cultural belonging and share a common identity. Bridging social capital refers to mutual relations of people (or groups) who did not know each other before or who were unlikely to know each other. While bonding social capital facilitates cooperation within a dense group, bridging social capital facilitates interaction and cooperation among different people and groups in the sphere of civil society. Bonding social capital and bridging social capital have different outcomes and different functions in achieving economic goals. Putnam (2000) and de Souza Briggs (1998) characterize strong ties as a source of emotional and practical support that helps people in "getting by", while weak ties provide people with information and references for "getting ahead" in their lives and careers.

Distinguishing bridging and bonding social capital is, however, not simple or straightforward. Networks of family, friends and neighbours are usually included to bonding social capital, since they are considered to bring together people who are alike one another. Civic participation, on the other hand, is usually included to bridging social capital, since, as often stated, it brings together people who are unlike others. (Putnam and Goss, 2002). In modern urban environments, it is, however, not clear that neighbours are alike one another, share a common identity or the same information. It is also possible that civic participation does not bring in people from different social circles, if associations gather together people who are alike one another. Furthermore, there are networks, such as workbased networks, which often bring together people from different social circles but similar occupational and professional backgrounds. Thus, the distinction between bonding and bridging social capital is, basically, an ideal typical construction. In real life, the two dimensions often overlap.

Granovetter's work has inspired many further studies exploring the link between social networks, employment opportunities and promotion. Studies at the organization level indicate that favourable network positions inside organizations are related to better pay and early promotion (Burt, 1992; Podolnyand Baron, 1997; Gabbay and Zuckerman, 1998; Seibert et al., 2001). A study conducted among Dutch top managers showed that managers found their jobs largely through informal channels, and more so, if they possessed more social capital. According to the study, social capital, such as external work contacts and memberships in associations, also has a substantial independent influence on the income of managers (Boxman et al., 1991). There are studies (e.g. Mouw, 2003; Pellizzari, 2010) from the United States which suggest that the use of personal contacts in job searching does not result in any wage advantage for job seekers. McDonald (2015), however, shows that network-based job finding brings substantial wage returns, especially for individuals who were informally recruited into their jobs. According to him, contacts generate wage premiums among middleand high-wage jobs, but not in low-wage jobs. There is also evidence that social capital helps
Effect of early career social capital

1375 
IJSSP

$40,11 / 12$

1376 the unemployed to find a job. Korpi (2001), for example, discovered in Sweden that social networks enhance the potential of the unemployed to find a job. He concluded that the lack of social networks might be a factor behind prolonged unemployment. Yet according to Korpi, the transition from unemployment to employment did not have a specific connection to tie strength in Sweden. In the context of centralized economy, such as China, personal networks are used to gain influence from job-assigning authorities rather than to find employment information from market. In such an institutional context, jobs can be channelled through strong ties more easily than through weak ties. (Bian, 1997)

Thus, there are at least two mechanisms via which social capital may enhance individual income development. Networks may help individuals to get a better-paid job or to shorten their unemployment spells.

There are, however, controversies about the relative importance of strong and weak network ties in career development. Furthermore, in addition to finding the positive effects of social capital, some scholars have pointed out that investments in social capital may turn excessive and economically ineffective for an individual. According to Burt (1992), if large amounts of time are allocated to social ties which do not open up extra opportunities or information, the benefits of social capital are ineffective in economic terms. Investing time in sociability probably also decreases the time available to invest in more productive careerpromoting activities.

\section{Differentiated social capital}

Furthermore, social capital may also be a potential source of social inequalities and wage differences. Disadvantages of social capital have been explored among different social groups such as women, low-status workers, the unemployed and ethnic groups (e.g. Portes, 1998; Smith, 2000; Lin, 2001; McDonald and Elder, 2006; McDonald, 2011; Lutter, 2015; Behtoui, 2016; Verhaeghe et al., 2015; Bonoli and Turtschi, 2015). Theoretical approaches deriving from Pierre Bourdieu and Nan Lin have become valuable in explaining the mechanisms of social capital as bases for social inequalities.

According to Bourdieu (1986), the distribution of social capital is connected to other forms of capital, especially to cultural and economic capital. In order to function as capital, social capital requires individuals to have certain dispositions such as cultural competence that enable the establishment of valuable social relations. Thus, capital is convertible, meaning that it can be converted into another type. The transformability of capital is a way to accumulate capital. Transformability enables social capital to function as a backing for trust and references within the labour market, which may be converted into economic capital such as better income. According to Bourdieu, social capital is closely related to individuals' position in the social structure, meaning that those who are high in cultural and economic capital usually benefit from higher social capital and resources, whereas those low in capital have less potential in their social capital. Along with other forms of capital, social capital reproduces social inequalities and social closure.

Lin (2000) proposes two principles that lead to the group-specific differentiation of social capital: structural processes and homophily (see McPherson et al., 2001). The first principle is that social groups have differential access to social capital based on their social standing. While resources are embedded in social structures and attached to social positions, those in higher social positions benefit from their accessibility to better resources than those in lower/ inferior social positions accessing poorer resources as conducted through their networks. The second principle is that individuals tend to associate and bond with similar others. Those in superior social positions, with resource-rich networks, tend to associate with people from similar socio-economic backgrounds, while those in inferior social positions and with poorer resources tend to associate with people in positions similar to their own, resulting in poorer networks. 
Disadvantaged groups by gender and social class

Lin (2000) suggests that the male-dominant societal structure provides unequal access to social capital for women. Men profit from the embeddedness of their networks within larger organizations and their connections with higher positions. Gender constraints are reproduced along with a segregated labour market because men in higher positions tend to connect with other men, profiting from valuable information about job offers, while women associate more with other women.

The distribution of real-world social networks may not differ significantly between genders (Caldwell and Peplau, 1982; Dunbar and Spoors, 1995; McPherson et al., 2001; Miritello et al., 2013). Yet there are differences in their type and embeddedness and communication patterns. Women tend to maintain smaller social groups than men (Miritello et al., 2013; McPherson et al., 2001) and represent higher level of sex homophily (Kovanen et al., 2013; McPherson et al., 2001). Women are found to be more expressive in their communication patterns and they invest more time in affiliating social relations, while men are less talkative and more goal-oriented (Smoreda et al., 2000; Onnela et al., 2014). Traditionally, women's networks have consisted more of family and kin ties than those of men, who have more relations outside of kin and with their co-workers (e.g. Fischer and Oliker, 1983; Wellman, 1985; Marsden, 1987; Moore, 1990; Dunbar and Spoors, 1995). Men are reported to have wider occupational range in their networks than women (Campbell, 1988). Male networks also consist more of higher status connections (to other men) through which they can access more relevant job information (Brass, 1985; Ibarra, 1992; 1997; McDonald, 2011). Men are also connected to bigger voluntary organizations that are closer to economic life (McPherson and Smith-Lovin, 1982). In particular, when a family has small children, women tend to be more occupied in domestic affairs and their networks diminish (Munch et al., 1997). However, for example, Moore (1990) found that differences in the composition of men's and women's networks diminish when employment, family structure and age factors are controlled.

Similarly, an individual's network range has been related to the higher potential for status and income attainment (Campbell et al., 1986). Individuals with resource-rich networks are characterized by richness in the size and diversity of socio-economic strata, influential contacts and positions. Those in higher social positions are more likely to connect with those who have better access to resources, while people in lower socio-economic positions lack such influential connections (Campbell et al., 1986). Better social resources are often associated with weak ties (Lin et al., 1981; Lin and Dumin, 1986; Marsden and Hurlbert, 1988). Yet studies have shown that weak ties may not benefit those in lower socio-economic positions if the networks do not reach above their socio-economic cluster (Smith, 2000; Tassier, 2006; see also Campbell et al., 1986). For example, Smith (2000) found that the way women use their weak ties does not differ from that of men, but the benefits are in relation to the social status of the contact mobilizing them. She concluded that among women, the use of weak ties appears to be beneficial for those in high-status occupations, but inconsequential for those in low-status occupations. Studies show that women in high-advancement potential have wider information networks than their male counterparts and they can profit from more open and diverse networks (Ibarra, 1997; Lutter et al., 2015). Furthermore, Yang et al. (2019) found recently that high-placing women also benefit from having a female inner circle with their peers (who are connected to separate third-party contacts). They suggest that the dualistic composition of weak and strong (homophilous) ties may enable women to access to both diverse job market information and gender-specific tacit information to reach in leadership positions (Ragins et al., 1998).

Personal networks play different role within different societies and institutional contexts. In culturally and politically very different institutional contexts, such as the United States and China, social connections are in an important role of getting a job. (DiTomaso and Bian,
Effect of early career social capital

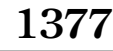


IJSSP

$40,11 / 12$

1378

2018). In some other institutional contexts, using personal connections may be understood as a corruption of the job search process (Sharone, 2014). Furthermore, in East Asia, the formation of social capital is based on more hierarchic and gendered structuration of the society and kinship, which is related to differential access and mobility in labour market for men and women (Chua and Wellman, 2016).

Nordic countries are highly rated in social equality in terms of gender and social class. In the Nordic context, it has also been stated that networks are less likely to be of great importance for labour market mobility, because there are nationwide systems of public employment agencies, and job information is obtainable from the agencies (Korpi, 2001). Furthermore, in the Nordic countries, universal welfare-state institutions increase generalized social trust (Kumlin and Rothstein, 2005), which diminishes the importance of individual-level social ties. According to Håkansson and Tovatt (2017), formalized institutions largely replaced networks of social capital with regard to recruitment practices in social democratic welfare states regime. According to them, however, social networks have become more important in the recent decades also in the welfare state context.

\section{Aims}

The studies presented earlier indicate that social networks as social capital intensify the potential of getting a (new) job or moving on in one's career, both of which have a positive effect on income. As noted earlier, differential access to social capital for different social groups may contribute to inequality in labour market. These kinds of inequalities are often linked to social hierarchies (Lin, 2000). In this study, we focus on individual social capital adding value to personal income within different social groups in the Nordic context.

Our main research questions are: (1) do the size and composition of social networks differ by gender and socio-economic status among Finnish employees; (2) does social capital embedded in early career social networks have a positive effect on yearly earned income, and does this effect result from acquiring a more highly paid position or via avoiding unemployment; and (3) do men and those having higher socio-economic positions benefit more from social networks, that is, is the effect of social capital on earned income stronger for those in more favourable positions?

We expect that resources embedded in social networks have a more positive outcome on personal income among high-status men and women. If networks are capable of conducting economic outcomes and information about labour markets, then higher long-term income should be measured for men and women who have wider networks.

\section{Data and methods \\ Data}

The data consist of the cross-sectional FLCS conducted in $1994(N=8,650)$ by Statistics Finland, which has been combined with annual register-based follow-up data on yearly earned incomes from Statistics Finland. The register data on earned incomes covers the years 19952016 and incorporates earned income from main and secondary jobs during reference year with 100 Euro interval. The FLCS is a representative of the Finnish population over 15 years old covering several themes, such as family and other social relationships, working life and unemployment, leisure activities, physical health and psychic and social well-being. The data were collected by face-to-face interviews during the winter and spring of 1994 with a $73 \%$ response rate. The FLCS sampling frame was a systematic random sample with stratification by home municipality, occupational class and income. The combination of the survey and register-based data was approved and performed by Statistics Finland using personal identity code. Our analyses are restricted to 25-35-year-old employees during the 1994 interview ( $N=816$ individuals with 21,371 individual-year observations for earned income). 


\section{Measures}

Information on individual earned incomes per year (1995-2016) comes from the Finnish Tax Administration registers and covers all non-institutionalized persons currently living in Finland, excluding those without an address. The highest percentile of earned incomes was coded with the group average. We further coded earned incomes as missing (instead of 0 ) for deceased persons from the year they had died onwards. This was possible, as the register incorporated information on whether or not a person was deceased and the year in which this had happened. However, the register data does not include information on whether a person has moved abroad. A person permanently living and working abroad has no taxable income in Finland and thus, has no information on earned income (defined as 0).

Our social capital measure is threefold. We measure, first, the extent of primordial ties, second, the extent of work-related ties and third, the extent of civic ties. We measure the extent of primordial ties with questions addressing the frequency of meeting parents or siblings not living in same household. These two questions are combined into a single variable indicating the maximum level of either of the two items. Thus, this variable measures the extent of time one devotes to socializing with his or her close relatives. The extent of workrelated ties is measured with question about the frequency of spending free time with coworkers. The response categories for all aforementioned questions were: $0=$ none, $1=$ less than once a year or never, $2=$ once or twice per year, $3=$ approximately once in a month, $4=$ approximately once in a week and $5=$ almost daily. We exclude "none" responses from our analyses for all variables, as this category is problematic for the interpretation of results. The category meeting parents and siblings is very heterogeneous and includes those who live in their parental home (and have no siblings living in another household), but also those living in their own household and having no living parents or siblings. Similarly, the category spending free time with co-workers refers both to those who do not have any co-workers, that is, who work alone and to those that have co-workers, but never meet them during free time. We rescale variables to three-category versions: $0=$ less than once a year or never and once or twice per year; $1=$ approximately once in a month; and $2=$ once a week or daily. In addition, we use a question addressing the frequency of participation in associational, civic or other societal activities to measure the extent of civic ties. The response categories for this item were: $1=$ not at all, $2=$ occasionally, $3=$ less than weekly but regularly and $4=$ regularly once a week. We will use a three-category version of this variable for which the two middle categories, that is, occasionally and less than weekly, are combined into one $(0=$ not at all; $1=$ occasionally; and 2 = regularly). Only the three-category versions of these variables are used in analyses in order to gain insight to possible non-linear effects while retaining large enough sample size for each category.

The individuals' socio-economic status is measured with the standard socio-economic classification defined by Statistics Finland. The classification takes account of a person's occupation and employment status and is supplemented by divisions describing the nature of the occupation and industry. The Finnish official socio-economic classification is an evolved version of the old Nordic socio-economic classification, but with a stronger emphasis on skill differences and educational requirements. In general, the Finnish classification may be interpreted similarly to the Erikson-Goldthorpe classification (Erikson and Goldthorpe, 1992). For the purposes of this study, socio-economic status is classified into three groups of employees: (1) blue-collar workers, (2) lower white-collar workers and (3) upper white-collar workers.

Earlier studies show that people with higher educational level participate more in social networks, and they are more engaged in volunteering networks (e.g. Brehm and Rahn, 1997; Van Oorschot and Arts, 2005). Accordingly, some empirical studies have found that when the education factor is controlled, the link between bridging social capital and income disappears (e.g. Bridges andVillemetz, 1986), or it remains only among high-status employees (Wegener,
Effect of early career social capital

1379 
IJSSP

$40,11 / 12$

1380
1991). Thus, when analysing the association of social capital to income, it is essential to control for education.

Along with education we use age group, family status, employment sector, weekly working time, type of employment contract and job tenure as background factors. All background factors are time-invariant variables, that is, their values do not change over time. In addition, we use register data on yearly unemployment months to test whether differences in annual earned incomes are the result of higher monthly incomes or less unemployment. If the effect of measures of social capital diminishes or disappears when unemployment months are introduced to the model, this indicates that the difference in yearly income was explained by differences in unemployment months. However, if the effects remain unchanged, then the difference should derive from higher monthly earnings. We also use yearly register information on received parental and child home care allowance payments in Euros from Kela (Finnish Social Insurance Institution) in order to control for parental leaves during the followup. Unemployment months and care allowances are time-varying variables, that is, their values change during the follow-up years. All register information is complete, that is, there are no missing values for these variables. The descriptive information of independent and dependent variables is presented in supplementary tables S1 and S2.

\section{Methods}

First, we analyse how the level of network capital varies according to gender, socio-economic status and different background factors using ordered logistic regression models. Secondly, we employ linear growth curve models to estimate the effect of early career social capital on later income development (1995-2016). We use cross-product terms to test whether the effect of social capital on income is larger for males and those in higher socio-economic positions and whether the level of social capital measures affects the development of earned incomes.

Ordered logistic model is a generalization of standard binary logistic model for response variables that have more than two ordered categories. There are several types of ordered logistic regression models. We will employ proportional odds cumulative logit model in which the ordered categorical variable is treated as a categorized version of an underlying latent continuous variable, as is often the case with, for example, Likert-scale variables. The cumulative logit model compares the probability of being at or below a certain level of the outcome to the probability of being beyond that level. A key assumption of the cumulative logit model is the proportionality of odds, that is, that the logit coefficients are equal across the different cut points or levels of outcome variable. The intercept or cut point is the only coefficient that changes across logit equations. Thus, the results are presented with a single set of coefficients for each variable as in OLS or binary logit model (Fullerton, 2009).

The assumption of proportional odds was met in all estimated models.

A growth curve model is essentially a random effects multilevel model applied to longitudinal data (Singer and Willet, 2003; Hox, 2010). Individuals serve as the highest level units (level 2) and repeated measures as the lowest level units (level 1) nested within individuals. In this model, each individual has his or her own growth trajectory, with the slope coefficient varying between individuals. Models with random intercept only or random intercept and slope did not fit the data as well as random slope only model. A growth curve model has several advantages over more traditional models, such as repeated measures ANOVA or MANOVA. One of the main advantages of growth curve models over traditional ones is that repeated measures can be taken on varying occasions, that is, the model does not require balanced data and thus, can handle incomplete data due to missing measurements. We use first-order autoregressive covariance structure for the repeated measures (level 1) and unstructured covariance structure at the individual level (level 2) to estimate the random slope. The time variable is coded as years since the start of follow-up (year 1995 is coded as zero, 1996 as one, 1997 as two, etc.) and is used as a linear predictor in the models. With this 
coding of the time variable, the intercept can be interpreted as the expected earned incomes at the first follow-up year, that is, in 1995.

\section{Results \\ Differentiation of social capital}

Our first aim is to analyse how the level of social capital varies according to gender, socioeconomic status and different background factors. The results from ordered logistic regression models are presented in Table 1 . We estimated three models for each of the three social capital measures. The firs model (A) includes main effects of gender and socioeconomic status. In the second model (B), background factors are added. In the third model (C), we added cross-product terms for gender and socio-economic status in order to test whether the gender difference in social capital is dependent on the socio-economic status and vice versa.

In the first model, there is significant gender difference with regard to how often one spends free time with his or her co-workers: men meet co-workers more often at free time. However, this effect loses its significance at the $5 \%$ risk level when background factors are added to the model. However, the gender difference stays significant at the $10 \%$ risk level. A more detailed analysis reveals that this reduction in effect is caused by introducing family status to the model as men were more often single. By contrast, the gender differences with regard to civic participation became significant at the $5 \%$ level only after background factors are controlled for. Again, men participate in civic activities more often than women do. This increase in effect is caused by introducing employment sector to the model as women were more often working in the public sector.

The differences between socio-economic groups were evident for all three measures of social capital. Both upper and lower white-collar employees meet their relatives less often when compared to blue-collar workers. This difference is reduced only slightly after background factors are added to the model. By contrast, lower white-collar and especially upper white-collar employees participate in civic or associational activities more actively than blue-collar employees do. These effects are reduced somewhat after controlling for background factors, but remain nonetheless significant. The effect of socio-economic status on spend free time with co-workers becomes significant only after background factors are added to the model: upper white-collar employees spend more often free time with their coworkers than blue-collar workers.

The differences between age groups in social capital measures are clearly smaller. Younger participants spend free time with their co-workers more often. Differences in family status are largest with regard to meeting co-workers during free time, and they echo the age group differences: singles meet co-workers more often than couples with children. By contrast, singles and couples without children meet their parents or siblings less often than couples with children. The differences by education level is significant only for civic participation. Those with tertiary education participate in civic or associational activities more often than those with primary education. In addition, compared to private sector, respondents working in the public sector participate more often to associational or civic activities. Finally, we found no significant interaction effects between gender and socioeconomic status on measures of social capital (model C).

The results reveal that also in Nordic context, social capital is to a certain degree genderand class-dependent. Men are more active in civic participation, but with regard to meeting relatives or co-workers, we find no significant gender differences. The socio-economic differences, on the other hand, are quite clear in the both dimensions. In lower-socio-economic groups, the composition of social capital is concentrated on family ties. The higher-socioeconomic groups, instead, socialize more often with their workmates. They also have more
Effect of early career social capital 
IJSSP

$40,11 / 12$
Table 1.

Ordered logistic regression models of social capital measures on background factors for 25-35-year-old employees in 1994 (ordered logit coefficients)
Meeting parents or siblings living in another household $^{\mathrm{a}}$

$$
\begin{aligned}
& -0.91 \text { *** } \\
& -0.41 * * \\
& 861.04 \\
& 884.64 \\
& 26.30 * * * \\
& -2.33^{* * *} \\
& -0.81 * * * \\
& -0.02
\end{aligned}
$$

$\begin{array}{ll}\text { B } & \text { Gender male } \\ & \text { Socio-economic status }\end{array}$ (ref. blue-collar) Upper white-collar Lower white-collar Age 25-29 years

Family status (ref. couple with children)

Single parent

Single

Couple, no children

Education (ref.

primary)

Tertiary

Secondary

Public sector (ref.

private)

Working part-time (ref. $35 h+$ /week)

Temporary work

contract (ref. fixed-

term)

Job tenure less than year

(ref. One year or more)

AIC

BIC

LR test

Cut point $1(Y=0)$

Cut point $2(Y=1)$

Model Male*upper white-

$\mathrm{C}^{\mathrm{c}} \quad$ collar

Male*lower whitecollar

AIC

BIC

LR test

865.14

935.92

867.03

947.26

Cut point $1(Y=0)$

Cut point $2(Y=1)$ $N=828$

0.01

$$
\begin{gathered}
-0.78^{* *} \\
-0.37^{*} \\
0.24
\end{gathered}
$$

$$
\begin{gathered}
0.18 \\
-0.44^{*} \\
-0.55^{* *}
\end{gathered}
$$

0.10

0.21

$-0.04$

$-0.09$

$-0.21$

0.04

$28.94 * *$

-2.36 ****

$-0.82^{* *}$

$-0.55$

$-0.31$

Spending free time with colleagues $^{\mathrm{a}}$ $N=830$

$0.35 *$

0.27
-0.19
845.27
868.88
$78.47^{* * *}$
$0.76^{* * *}$
$2.09^{* * *}$
$0.29 \dagger$

$0.84^{*}$
-0.07
$0.45^{* *}$

$0.92 * *$

$0.60 * *$

$-0.02$

$$
0.10
$$

$0.70 * * *$

$-0.19$

0.16

$-0.24$

$-0.16$

$-0.28$

$-0.09$

$0.74 *$

0.34

0.37 *

$-0.05$

$-0.14$

0.05

0.15

$-0.08$

$-0.12$

827.67

831.00

898.64

901.82

65.34***

$1.00^{* * * *}$

2.38 ***

0.64

77.24 w.

$1.79 * * *$

2.90 ***

0.01

0.40

0.13

$29.66^{*}$

$-2.17 * * *$

$-0.64^{*}$
832.18
912.44
$62.84^{* * * *}$
$0.78^{*}$
$2.16^{* * *}$

831.52

911.94

79.46 ***

$1.75^{* * * *}$

$2.86^{* * * *}$

Note(s): ${ }^{2}$ Response categories: $0=$ maximum twice per year; $1=$ approximately once in a month; and $2=$ once a week or daily

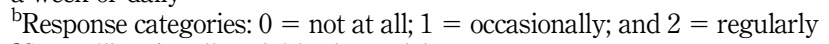

${ }^{\mathrm{c}}$ Controlling for all variables in model 2

$\dagger p<0.10 ; * p<0.05 ; * * p<0.01 ; * * * p<0.001$ 
social capital in the form of civic participation. We are not, however, able to measure the nature of this civic activity, that is, whether there are differences between various groups in participation to different kinds of civic activities.

\section{Social capital and long-term income development}

Next, we will analyse how measures of social capital predict income development during the 21-year follow-up period (1995-2016) and whether this effect is dependent on gender or socioeconomic status. Table 2 presents the results from the linear growth curve models. The analysis is conducted in four stages. The first model includes only the measures of social capital (model 1). In the second stage, gender, socio-economic status and background factors are added into the model (model 2). In the third stage, we add unemployment months and parental allowances (model 3). In the last model, we add cross-product terms of measures of social capital with gender and socio-economic status (model 4). Of the random coefficients, only random slope was significant in all models. As expected, there is also a significant positive correlation in individuals' earned incomes between any two successive years in all models (Rho),

In the uncontrolled model (model 1), participation in civic activities or meeting co-workers during free time increases earned incomes at the beginning of the follow-up period, that is, in 1995. In the case of civic participation, it is the high activity group that stands out from the rest. Those who participate in civic activities frequently have higher incomes than others do. Meeting co-workers monthly or a few times a year, that is, "the middle group" seems to be the most beneficial with regard to income. However, when gender, socio-economic status and background factors are added to the model (model 2), these coefficients decrease considerably, especially with regard to civic participation, and lose their significance at the $5 \%$ risk level. After the introduction of unemployment months and parental allowances in the third model, the "middle group" of meeting co-workers regains its significance at the $5 \%$ level. Thus, the uncontrolled effects of civic participation on earned income seem to reflect mainly gender and socio-economic differences in income. However, meeting co-workers on monthly basis seems to increase earned income at the beginning of observation period even after controlling for gender and socio-economic status. As was evident in the analyses presented in Table 1, gender and especially socio-economic status were connected to the level of social capital. From the second and third model, it is evident that gender and socio-economic differences in earned income are large, especially the latter. In the last model, we added crossproduct terms to test whether the effect of social capital on earned incomes is larger for males and those in higher socio-economic positions. None of these cross-product terms was significant indicating that the effect of social capital on incomes is independent of gender or socio-economic position.

Social capital may affect not only the level of earned incomes at a given point in time but also the degree of development in incomes. In other words, high social capital is probably associated with more rapid increases in earned incomes during the follow-up period. To test this hypothesis, we added cross-product terms for measures of social capital and a time trend to model 2 presented in Table 2. We found significant time trend interactions at the $5 \%$ risk level for all three measures of social capital (see Supplementary Table S3). These interactions mean that the rapidness of income increase is dependent on the frequency of meeting relatives or co-workers and civic participation. In Figure 1, we present income development separately for different levels of the three social capital measures. The figure reveals that income development during the observation period was faster for those who participated in civic activities occasionally or regularly compared to the non-participant group. Similarly, those who met their relatives or co-workers on a monthly basis have more positive income development than those who met relatives or co-workers very rarely. Again, it seems that "the middle group" is most cost-efficient with regard to income development.
Effect of early career social capital

1383 
IJSSP
$40,11 / 12$

1384

\begin{tabular}{|c|c|c|c|c|}
\hline & Model 1 & Model 2a & Model 3a & Model 4a \\
\hline Intercept & $19,201^{* * * *}$ & $12,420 * * *$ & $14,429 * * *$ & $15,105^{* * * *}$ \\
\hline Year trend $(0-21)$ & $1087^{* * * *}$ & $1094^{* * * *}$ & $1071 * * *$ & $1071 * * *$ \\
\hline \multicolumn{5}{|l|}{ Meeting relatives (ref. max twice per year) } \\
\hline Monthly & 1012 & 952 & 973 & 532 \\
\hline At least weekly & -1952 & -402 & -93 & -431 \\
\hline \multicolumn{5}{|l|}{ Meeting co-workers (ref. max twice per year) } \\
\hline Monthly & $2,613^{* *}$ & $1658 \dagger$ & $1691^{*}$ & 887 \\
\hline At least weekly & 1087 & 1121 & 1196 & 1545 \\
\hline \multicolumn{5}{|l|}{ Civic participation (ref. not at all) } \\
\hline Occasionally & $2,559 *$ & -60 & 9 & -1437 \\
\hline Regularly & $4506^{* * * *}$ & 665 & 409 & -254 \\
\hline Gender male & & $8,951 * * *$ & 7609 **** & $4907 * *$ \\
\hline \multicolumn{5}{|l|}{ Socio-economic status (ref. blue-collar) } \\
\hline Upper white-collar & & $11,632 * * *$ & $11,320 * * *$ & $12,465 * * *$ \\
\hline Lower white-collar & & $2,337^{*}$ & 2029* & $1987^{*}$ \\
\hline Unemployment months/year & & & $-1386^{* * * *}$ & $1386^{* * * *}$ \\
\hline Parental allowances $100 € /$ year & & & $-119 * * *$ & $-119 * * *$ \\
\hline \multicolumn{5}{|l|}{ Interactions } \\
\hline Male*meeting relatives monthly & & & & 1841 \\
\hline Male*meeting relatives weekly & & & & 2025 \\
\hline Male*meeting co-workers monthly & & & & 631 \\
\hline Male*meeting co-workers weekly & & & & 988 \\
\hline Male*civic participation occasionally & & & & 1635 \\
\hline Male*civic participation regularly & & & & 3134 \\
\hline $\begin{array}{l}\text { Upper white-collar *meeting relatives } \\
\text { monthly }\end{array}$ & & & & -883 \\
\hline $\begin{array}{l}\text { Upper white-collar *meeting relatives } \\
\text { weekly }\end{array}$ & & & & -1812 \\
\hline \multicolumn{5}{|l|}{$\begin{array}{l}\text { Upper white-collar *meeting co-workers } \\
\text { monthly }\end{array}$} \\
\hline \multicolumn{5}{|l|}{$\begin{array}{l}\text { Upper white-collar *meeting co-workers } \\
\text { weekly }\end{array}$} \\
\hline \multicolumn{5}{|l|}{$\begin{array}{l}\text { Upper white-collar *civic participation } \\
\text { occasionally }\end{array}$} \\
\hline \multicolumn{5}{|l|}{$\begin{array}{l}\text { Upper white-collar *civic participation } \\
\text { regularly }\end{array}$} \\
\hline \multicolumn{5}{|l|}{ Random coefficients and fit } \\
\hline $\begin{array}{l}\text { AR1 diagonal } \\
\text { AR1 Rho }\end{array}$ & 222479006 & 187683445 & 171158405 & 170592226 \\
\hline AR1 Rho & 0.79 & 0.75 & 0.75 & 0.75 \\
\hline Slope & 2362889 & $\begin{array}{r}1843481 \\
377257\end{array}$ & 1790038 & 1789848 \\
\hline-2 Log likelihood & 377764 & 377257 & 375653 & 375643 \\
\hline
\end{tabular}

Table 2.

Estimates from linear growth curve models predicting development of earned income (Euros) from 1995 to 2016 for 25-35year-old employees in $1994(N=820)$

employment sector and part-time work

$\dagger p<0.10 ; * p<0.05 ; * * p<0.01 ; * * *<0.001$

\section{Discussion}

Previous studies on social capital have suggested that social capital has a positive impact on individuals' success in labour market by enhancing their career and income development. Simultaneously it has been indicated that the type and the embeddedness of social capital differentiate according to gender and social background. Men and people in higher social 


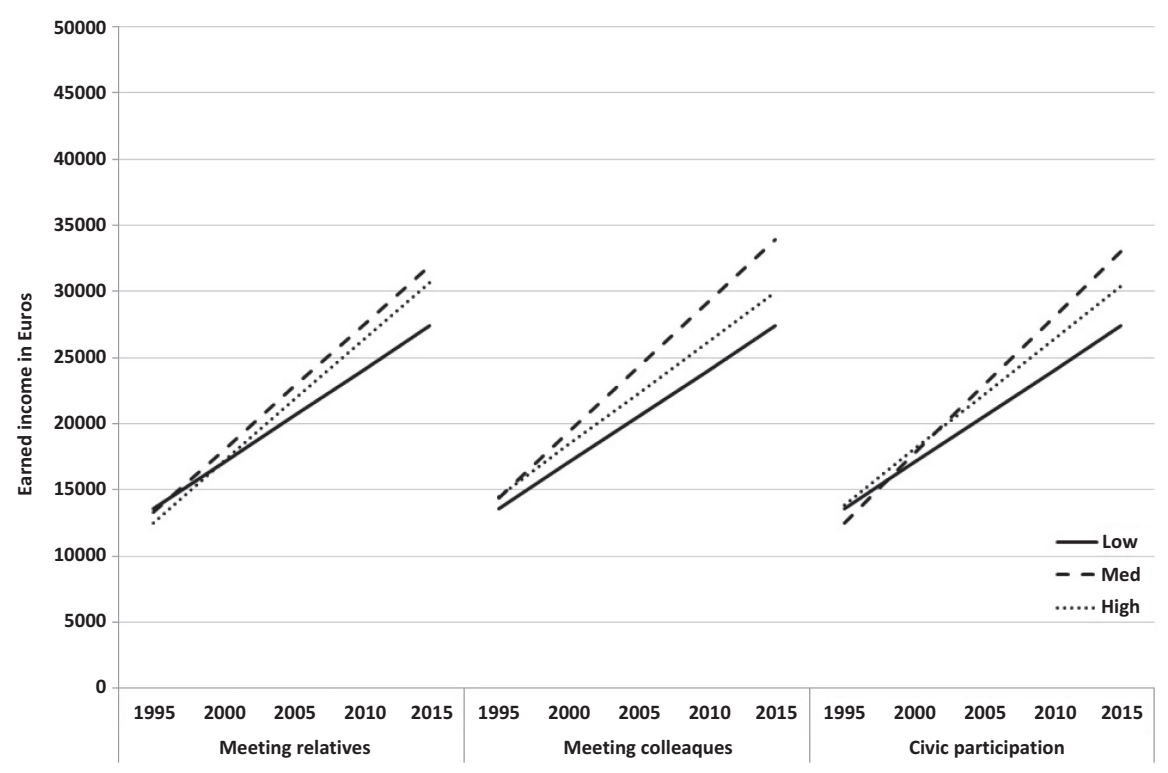

Effect of early career social capital

1385

positions are stated to profit more of their networks, since the quality of the networks provides them better access to profitable information and references. Lin (2000) suggests that these advantages (and disadvantages) in social capital are related to structural constraints and social hierarchies. This may not be the case in more equal welfare societies.

In this article, we investigated to what extent men and women and employees from different socio-economic statuses differ with regard to the type and extent of their social networks in Finland, that is, in the Nordic welfare state context. We also analysed how the early career social capital embedded in individuals' social networks was connected with the employees' long-term income development and whether social networks contribute to income development differently depending on gender and socio-economic status. The linear growth curve analyses were based on representative FLCS from the year 1994 combined with register data on earned incomes from 1995 to 2016. We used questions addressing the frequency of meeting parents or siblings, spending free time with co-workers and participation in associational, civic or other societal activities as measures of the extent of social capital.

We found that there were no large differences between men and women regarding their composition of social capital in frequency of meeting parents or siblings, frequency of spending free time with their co-workers or in frequency of participation in associational, civic or other societal activities. Gender differences were found only with regard to associational or civic participation after controlling for various background factors. Men participated more often than women in civic activities. Differences between socio-economic groups were evident for all three measures. Those in higher socio-economic positions met their relatives less frequently, spent free time with co-workers more often and participated more often in civic or associational activities. Thus, it appears that the Nordic model, in which women participate actively in the labour market, equalizes somewhat the distribution of social capital between men and women. In addition, we found that differences between socio-economic groups in composition of social capital were similar for both men and women, that is, there was no interaction effect between these two. 
IJSSP

$40,11 / 12$

1386

The composition of individual's social capital affects income development also in the Nordic context. Using linear growth curve models, we found that after controlling for background factors, meeting co-workers during free time had significant increasing effect on earned incomes at the beginning of observation period, that is, 1995. We found no evidence that men or those in high socio-economic positions profit more of their networks in economic terms. This finding is in accordance with Lin's (2000) expectations concerning the role of networks in welfare societies. However, there were significant time trend interactions with regard to all measures of social capital, that is, the degree of income increase during the follow-up was dependent on the frequency of meeting relatives or co-workers and civic participation. Income development was faster for those who participated in civic activities at least occasionally or who met their relatives or co-workers on a monthly basis, that is, for the "middle group".

Our results give support to the idea that social capital can be transformed into economic capital. The results also imply that in economic terms it is important to balance diverse forms of social capital. Moderate-level investments to network capital seem to be the most beneficial with regard to the long-term income development. Using a lot of time to socialize with family relations (bonding) is economically inefficient in the long term. Similarly, for civic engagement and co-workers (bridging ties), moderate level of investment seems to bring at least the same level of economic gains as frequent participation.

This finding is in accordance with hypotheses that address social capital as potential source of social inequalities and wage differences. However, the effects of social capital seem to be quite modest in the Nordic context. One reason for that may be the effective role of welfare system that provides equal access for everyone to its services and information, also in the case of finding a job. In addition, universal welfare institutions enhance generalized trust in the society, which diminish the importance of using individual networks. At the policy level, a special emphasis should be directed to employees with low socio-economic position. These people are especially vulnerable as their low level of income is combined with network composition that is concentrated on intensive primordial ties, which in turn hinders their further income development.

There are some restrictions that should be taken into account when drawing conclusions from our analyses. Firstly, even though we use register data on long-term income development, our measures of social capital come from cross-sectional survey. Thus, we are not able to address the stability or accumulation of social capital during life course. This restriction will probably cause our analysis to underestimate the true effect of social capital on earned incomes. Secondly, our measure of civic participation differentiates the degree of active participation in civic or societal activities. We are not able to measure the nature of this civic activity, that is, whether there are differences between various groups in participation to different kinds of civic activities. These differences may explain some observations, that is, men benefiting more of active civic participation. Thirdly, we are not able to control for the fact that more sociable people are probably more capable of creating both bridging and bonding social capital. However, the interconnectedness of sociability and network capital does severely affect the interpretation of our results. Thus, there is need for further studies addressing this issue with a true panel data on both incomes and measures of social capital.

\section{References}

Behtoui, A. (2016), "Beyond social ties: the impact of social capital on labour market outcomes for young Swedish people", Journal of Sociology, Vol. 52 No. 4, pp. 711-724.

Bian, Y. (1997), "Bringing strong ties back in: indirect ties, network bridges, and job searches in China”, American Sociological Review, Vol. 62 No. 3, pp. 366-385. 
Bonoli, G. and Turtschi, N. (2015), "Inequality in social capital and labour market re-entry among unemployed people", Research in Social Stratification and Mobility, Vol. 42, pp. 87-95.

Bourdieu, P. (1986), "The forms of capital", in Richardson, J.G. (Ed.), Handbook of Theory and Research for the Sociology of Education, Greenwood, New York, pp. 241-258.

Boxman, E., De Graaf, P. and Flap, H. (1991), "The impact of social capital and human capital on the income attainment of Dutch managers", Social Networks, Vol. 13, pp. 51-73.

Brass, D.J. (1985), “Men's and women's networks: a study of interaction patterns and influence in an organization", Academy of Management Journal, Vol. 28, pp. 327-343.

Brehm, J. and Rahn, W. (1997), "Individual-level evidence for the causes and consequences of social capital”, American Journal of Political Science, Vol. 41, pp. 999-1023.

Bridges, W. and Villemez, W. (1986), "Informal hiring and income in the labor market", American Sociological Review, Vol. 51 No. 4, pp. 574-82.

Burt, R.S. (1992), Structural Holes: The Social Structure of Competition, Harvard University Press, Cambridge, MA.

Burt, R.S. (2000), "The network structure of social capital", Research in Organizational Behavior, Vol. 22, pp. 345-423.

Burt, R.S. (2002), "The social capital of structural holes", in Guillén, M.F., Collins, R., England, P. and Meyer, M. (Eds), The NewEconomic Sociology, Russell Sage Foundation, New York, pp. 148-192.

Caldwell, M.A. and Peplau, L.A. (1982), "Sex differences in same-sex friendship", Sex Roles: A Journal of Research, Vol. 8 No. 7, pp. 721-732.

Campbell, K.E., Marsden, P.V. and Hurlbert, J.S. (1986), "Social resources and socioeconomic status", Social Networks, Vol. 8 No. 1, pp. 97-117.

Campbell, K. (1988), “Gender differences in job-related networks”, Work and Occupations, Vol. 15, pp. 179-200.

Chua, V. and Wellman, B. (2016), "Networked individualism, East asian style", Oxford Research Encyclopedia of Communication, Oxford University Press, Oxford.

Coleman, J.S. (1988), "Social capital in creation of human capital”, American Journal of Sociology, Vol. 94, pp. 95-120.

de Souza Briggs and Xavier (1998), "Doing democracy up-close: Culture, power, and communication in community building", Journal of Planning Education and Research, Vol. 18, pp. 1-13.

DiTomaso, N. and Bian, Y. (2018), "The structure of labor markets in the US and China: social capital and guanxi", Management and Organization Review, Vol. 14 No. 1, pp. 5-36.

Dunbar, R.I. and Spoors, M. (1995), "Social networks, support cliques, and kinship", Human nature, Vol. 6 No. 3, pp. 273-290.

Erikson, R. and Goldthorpe, J. (1992), The Constant Flux: A Study of Class Mobility in Industrial Societies, Clarendon press, Oxford.

Fischer, C. and Oliker, S. (1983), "A research note on friendship, gender, and the life cycle", Social Forces, Vol. 62, pp. 124-132.

Fullerton, A.S. (2009), “A conceptual framework for ordered logistic regressionmodels", Sociological Methods and Research, Vol. 38 No. 2, pp. 306-347.

Gabbay, S.M. and Zuckerman, E.W. (1998), "Social capital and opportunity in corporate R\&D: the contingent effect of contact density on mobility expectations", Social Science Research, Vol. 27, pp. 189-217.

Gittell, R. and Vidal, A. (1998), Community Organizing: Building Social Capital as a Development Strategy, Sage Publications, Thousand Oaks.

Granovetter, M.S. (1973), “The strength of weak ties”, American Journal of Sociology, Vol. 78, pp. $1360-1380$. 
IJSSP

$40,11 / 12$

1388

Granovetter, M.S. (1974), Getting a Job: A Study of Contacts and Careers, University of Chicago Press, Chicago.

Granovetter, M.S. (1983), “The strength of weak ties: a network theory revisited”, Sociological Theory, Vol. 1, pp. 201-233.

Granovetter, M.S. (1995), Getting a Job: A Study of Contacts and Careers, 2nd ed., Harvard University Press, Cambridge, MA.

Håkansson, P. and Tovatt, C. (2017), "Networks and labor market entry - a historical perspective", Labor History, Vol. 58 No. 1, pp. 67-90.

Hox, J. (2010), Multilevel Analysis. Techniques and Applications, 2nd ed., Routledge, New York.

Ibarra, H. (1992), "Homophily and differential returns: sex differences in network structure and access in an advertising firm", Administrative Science Quarterly, Vol. 37 No. 3, pp. 422-447.

Ibarra, H. (1997), "Paving an alternative route: gender differences in managerial networks", Social Psychology Quarterly, Vol. 60 No. 1, pp. 91-102.

Knack, S. and Keefer, P. (1997), "Does social capital have an economic payoff? A cross-country investigation", Quarterly Journal of Economics, Vol. 112, pp. 1251-1288.

Korpi, T. (2001), "Good friends in bad times? Social networks and job search among the unemployed in Sweden", ActaSociologica, Vol. 44, pp. 157-170.

Kovanen, L., Kaski, K., Kertész, J. and Saramäki, J. (2013), "Temporal motifs revealhomophily, genderspecific patterns, and group talk in call sequences", Proceedings of theNational Academy of Sciences, Vol. 110 No. 45, pp. 18070-18075.

Kumlin, S. and Rothstein, B. (2005), "Making and breaking social capital. The impact of welfare state institutions", Comparative Political Studies, Vol. 38 No. 3, pp. 339-365.

Lin, N. and Dumin, M. (1986), “Access to occupations through social ties”, Social Networks, Vol. 8, pp. 365-385.

Lin, N., Ensel, W.M. and Vaughn, J.C. (1981), "Social resources and strength of ties: structural factors in occupational status attainment", American Sociological Review, Vol. 46, pp. 393-405.

Lin, N. (1999), "Building a network theory of social capital", Connections, Vol. 22, pp. 28-51.

Lin, N. (2000), "Inequality in social capital", Contemporary Sociology, Vol. 29 No. 6, pp. 785-795.

Lin, N. (2001), Social Capital. A Theory of Social Structure and Action, Cambridge University Press, Cambridge.

Lutter, M. (2015), "Do women suffer from network closure? The moderating effect of social capital on gender inequality in a project-based labor market, 1929 to 2010", American Sociological Review, Vol. 80 No. 2, pp. 329-358.

Marsden, P. (1987), “Core discussion networks of Americans”, American Sociological Review, Vol. 52, pp. 122-131.

Marsden, P.V. and Hurlbert, J.S. (1988), "Social resources and mobility outcomes: a replication and extension”, Social Forces, Vol. 66 No. 4, pp. 1038-1059.

McDonald, S. and Elder, G.H. (2006), "When does social capital matter? Non-searching for jobs across the life course", Social Forces, Vol. 85, pp. 521-549.

McDonald, S. (2011), "What's in the 'old boys' network? Accessing social capital in gendered and racialized networks”, Social Networks, Vol. 33 No. 4, pp. 317-330.

McDonald, S. (2015), "Network effects across the earnings distribution: payoffs to visible and invisible job finding assistance", Social Science Research, Vol. 49, pp. 299-313.

McPherson, J.M. and Smith-Lovin, L. (1982), "Women and weak ties: differences by sex in the size of voluntary organizations", American Journal of Sociology, Vol. 87 No. 4, pp. 883-904.

McPherson, M., Smith-Lovin, L. and Cook, J.M. (2001), "Birds of a feather: homophily in social networks", Annual Review of Sociology, Vol. 27 No. 1, pp. 415-444. 
Miritello, G., Lara, R., Cebrian, M. and Moro, E. (2013), "Limited communication capacity unveils strategies for human interaction”, Scientific Reports, Vol. 3 No. 1950, pp. 1-7.

Moore, G. (1990), "Structural determinants of men's and women's personal networks", American Sociological Review, Vol. 55, pp. 726-735.

Mouw, T. (2003),"Social capital and finding a job: do contacts matter?”, American Sociological Review, Vol. 68, pp. 868-98.

Munch, A., Miller McPherson, J. and Smith-Lovin, L. (1997), "Gender, children, and social contact: the effects of childrearing for men and women”, American Sociological Review, Vol. 62, pp. 509-520.

Onnela, J.P., Waber, B.N., Pentland, A., Schnorf, S. and Lazer, D. (2014), "Using sociometers to quantify social interaction patterns", Scientific Reports, Vol. 4 No. 5604, pp. 1-8.

Pellizzari, M. (2010), "Do friends and relatives really help in getting a good job?”, ILR Review, Vol. 63 No. 3, pp. 494-510.

Podolny, J.M. and Baron, J.N. (1997), "Resources and relationships: social networks and mobility in the workplace", American Sociological Review, Vol. 62, pp. 673-693.

Portes, A. (1998), "Social capital: its origins and applications in modern sociology", Annual Review of Sociology, Vol. 24 No. 1, pp. 1-24.

Putnam, R.D. (1993), Making Democracy Work: Civic Traditions in Modern Italy, Princeton University Press, Princeton, NJ.

Putnam, R.D. (2000), Bowling Alone. The Collapse and Revival of American Community, Simon and Schuster, New York.

Putnam, R.D. and Goss, K.A. (2002), "Introduction", in Putnam, R.D. (Eds), In Democracies in FluxThe Evolution of Social Capital in Contemporary Society, Oxford University Press, Oxford.

Ragins, B.R., Townsend, B. and Mattis, M. (1998), "Gender gap in the executive suite: CEOs and female executives report on breaking the glass ceiling”, Academy of Management Perspectives, Vol. 12 No. 1, pp. 28-42.

Seibert, S.E., Kraimer, M.L. and Liden, R.C. (2001), "A social capital theory of career success”, Academy of Management Journal, Vol. 44 No. 2, pp. 219-237.

Sharone, O. (2014), "Social capital activation and job searching: embedding the use of weak ties in the American institutional context", Work and Occupations, Vol. 41 No. 4, pp. 409-439.

Singer, J.D. and Willet, J.B. (2003), Applied Longitudinal Data Analysis: Modeling Change and Event Occurrence, Oxford University Press, New York.

Smith, S.S. (2000), "Mobilizing social resources: race ethnic and gender difference in social capital and persisting wage inequalities", The Sociological Quarterly, Vol. 41, pp. 509-537.

Smoreda, Z. and Licoppe, C. (2000), "Gender-specific use of the domestic telephone", Social Psychology Quarterly, Vol. 63 No. 3, pp. 238-252.

Tassier, T. (2006), "Labor market implications of weak ties", Southern Economic Journal, Vol. 72 No. 3, pp. 704-719.

Van Oorschot, W. and Arts, W. (2005), "The social capital of European welfare states: the crowding out hypothesis revisited", Journal of European Social Policy, Vol. 15 No. 1, pp. 5-26.

Verhaeghe, P.P., Van der Bracht, K. and Van de Putte, B. (2015), "Inequalities in social capital and their longitudinal effects on the labour market entry", Social Networks, Vol. 40, pp. 174-184.

Wegener, B. (1991), "Job mobility and social ties: social resources, prior job, and status attainment", American Sociological Review, Vol. 56, pp. 60-71.

Wellman, B. (1985), "Domestic work, paid work and network", in Duck, S. and Perlman, D. (Eds), Understanding Personal Relationships, Sage, London, pp. 159-191.

Yang, Y., Chawla, N.V. and Uzzi, B. (2019), “A network's gender composition and communication pattern predict women's leadership success", Proceedings of the National Academy of Sciences, Vol. 116 No. 6, pp. 2033-2038. 
IJSSP

$40,11 / 12$

1390

\section{Supplementary material}

Supplementary material is available for this article.

\section{About the authors}

Tomi Oinas is a senior researcher at the Department of Social Sciences and Philosophy, University of Jyväskylä, Finland. His main research interests include job quality, working time and time use. In an ongoing project, he examines the effect of non-standard working hours on employee well-being. His work has been published in the journals European Sociological Review, Acta Sociologica and Occupational and Environmental Medicine. Tomi Oinas is the corresponding author and can be contacted at: tomi.oinas@jyu.fi

Petri Ruuskanen is university lecturer of sociology at the University of Jyväskylä. In his research in the field of economic sociology, he has particularly examined the role of social capital in business networks and in working life. Recently he has studied the institutional change of Finnish civil society, third sector employment and job quality of NGOs. Recently his work has been published, for example, in the journals Employee Relations and Nordic Journal of Working Life Studies.

Mari Hakala is a $\mathrm{PhD}$ student and a project researcher in the Department of Social Sciences and Philosophy, University of Jyväskylä, Finland. Her current research interests comprise social isolation, loneliness and social and cultural capital. Her work has been published in Routledge Studies in Culture and Sustainable Development. Forthcoming articles in the journal Sosiologia and in SoPhi book.

For instructions on how to order reprints of this article, please visit our website: www.emeraldgrouppublishing.com/licensing/reprints.htm Or contact us for further details: permissions@emeraldinsight.com 